\title{
Postural stability and functional disorders in patients with loosened hip prosthesis
}

\author{
JUSTYNA DRZAŁ-GRABIEC ${ }^{1}$, ALEKSANDRA TRUSZCZYŃSKA-BASZAK ${ }^{2,3 *}$, ADAM TARNOWSKI ${ }^{4}$ \\ ${ }^{1}$ Institute of Physiotherapy, University of Rzeszów, Rzeszów, Poland. \\ ${ }^{2}$ Faculty of Rehabilitation, Józef Piłsudski University of Physical Education in Warsaw, Warsaw, Poland. \\ ${ }^{3}$ Professor A. Gruca Independent Public Research Hospital, Otwock Department of Orthopaedic Surgery, Otwock, Poland. \\ ${ }^{4}$ Faculty of Psychology, University of Warsaw, Warsaw, Poland.
}

\begin{abstract}
Purpose: The number of primary hip arthroplasties is growing every year. One of the most common long complications is the aseptic loosening of the prosthesis leading to serious complications in patients life, pain and following surgeries. In the literature, there is a lack of studies regarding balance impairment in this group of patients, which is why there was a need to conduct the study in order to find possible falling risk factors and simple functional, diagnostic test. The aim of the study was to assess functional state and static balance disorders in patients admitted to orthopaedic department due to loosened hip prosthesis prior to its replacement or removal. Methods: The study population were 30 patients ( 15 women and 15 men) admitted to Orthopaedic Department for diagnosis and treatment of loosened hip prosthesis. Patients' mean age was $71.67 \pm 9.21$, body height $169.20 \pm 8.75 \mathrm{~cm}$, body weight $77.83 \pm 12.96 \mathrm{~kg}$. The clinical control group consisted of 30 healthy subjects age-, body height- and weight-matched, without degenerative disorders of lower extremities. Function was assessed with Harris Hip score. The static balance test was conducted in the mornings, in quiet separate room on bi-modular stabilometric platform CQStab2P, registering the movement of centre of foot pressure (COP). Results: Measurements with eyes open and closed showed significant differences in limb loads - the load to the healthy limb was several times greater. Results of tests on the platform with eyes closed showed significantly worse balance in patients group. Their total statokinesiogram path was longer, and their COP sways number was greater. Similarly to the test with eyes open, the load of the healthy limb was much greater. Conclusion: Hip replacement loosening results in significant worsening of balance parameters. Balance assessment could be an additional useful diagnostic tool for hip replacement loosening available for physiotherapists.
\end{abstract}

Key words: postural stability, hip prosthesis loosening, balance disorders

\section{Introduction}

The number of primary total hip arthroplasties (THA) is growing every year [19]. Although the results are excellent, implant failure and revision continues to burden the healthcare system [3]. Dislocation are the main indication for revision THA (17.3\%), and mechanical loosening (16.8\%) [4], [7]. Several risk factors were described, including the surgical approach, the diameter of the head, impingement, component malposition, insufficient abductor muscles strength. In addition, there are also many treatment options, such as long-term bracing after closed reduction, component reorientation, increasing offset, exchange of the modular head and the polyethylene liner, insertion of constrained liner [5], [7].

Loosened prosthesis is a significant complication to patients health and requires a revision surgery. A diagnosis of loosened prosthesis is based on clinical symptoms and radiological examinations. There are no universally recognized standards for diagnosing of loosened prosthesis. This complication causes pain and instability, aggravated by activity and weight bearing [20]. Some hips with obviously loose prosthetic components are not painful causing problems with early

\footnotetext{
* Corresponding author: Aleksandra Truszczyńska-Baszak, Faculty of Rehabilitation, Józef Piłsudski University of Physical Education in Warsaw, Poland, ul. Marymoncka 34, 00-968 Warsaw, Poland. Phone: +48601566789, e-mail: aleksandra.rapala@wp.pl

Received: October 22nd, 2019

Accepted for publication: January 2nd, 2020
} 
diagnosis and adequate treatment [9]. A change to body balance parameters may be one of early symptoms of loosened hip prosthesis.

In clinical practice, stabilometric platforms are employed for the evaluation of patients' postural stability. These platforms monitor the movement in the centre of pressure $(\mathrm{CoP})$, subsequently, the motion is assessed by means of quantitative CoP indicators [13]. The measurements of body oscillation performed in standing position allows for both the assessment of function of postural control system, but also for diagnosing balance disorders and risk of falls [22].

This is why non-invasive methods available also in physiotherapeutic clinics are so important. They might result in a patient's earlier appointment with an orthopaedist. So far, there are no available studies in the literature that would discuss balance in patients with loosed hip prosthesis.

The aim of the study was to assess functional state and static balance in patients treated for loosened hip prosthesis prior to its replacement or removal.

\section{Materials and methods}

We received consent to conduct the study from the Senate Commission of Ethics of Scientific Research (SKE 01-21/2014), from the director of Independent Public Clinical Hospital, and written declarations from patients. In the years 2014-2017, we examined a group of 60 subjects coming from the whole territory of Poland. After obtaining signed informed consent to participate in the study, 30 patients ( 15 women and 15 men) prospectively admitted to the Independent Public Clinical Hospital of professor Adam Gruca in Otwock for diagnosis and treatment of loosened hip prosthesis were examined. Patients mean age was $71.67 \pm 9.21$, body height $169.20 \pm 8.75 \mathrm{~cm}$, body weight $77.83 \pm 12.96 \mathrm{~kg}$. The clinical control group consisted of 30 healthy subjects age-, body height-

Table 1. Biometric parameters of the studied groups

\begin{tabular}{|c|c|c|c|c|c|}
\hline & & & $\begin{array}{c}\text { Age } \\
\text { [years] }\end{array}$ & $\begin{array}{c}\text { Body } \\
\text { height }[\mathrm{cm}]\end{array}$ & $\begin{array}{c}\text { Body } \\
\text { mass }[\mathrm{kg}]\end{array}$ \\
\hline \multirow{4}{*}{ 芯 } & \multirow{2}{*}{$\begin{array}{l}\text { Study } \\
\text { group }\end{array}$} & $\bar{X}$ & 71.67 & 169.20 & 77.83 \\
\hline & & $\mathrm{SD}$ & 9.208 & 8.747 & 12.96 \\
\hline & \multirow{2}{*}{$\begin{array}{l}\text { Control } \\
\text { group }\end{array}$} & $\bar{X}$ & 70.23 & 168.93 & 75.69 \\
\hline & & $\mathrm{SD}$ & 8.685 & 7.520 & 11.91 \\
\hline & $p$ & & 0.441 & 0.778 & 0.819 \\
\hline
\end{tabular}

$x$ - arithmetic mean, $\mathrm{Me}-$ median, $\mathrm{SD}-$ standard deviation, MIN - minimum, MAX - maximum. and weight-matched, without degenerative disorders of lower extremities. We did not find statistically significant differences between the two groups. In Table 1, detailed data of the subjects are presented.

The criteria for subject inclusion in the study were the following: loosened hip prosthesis in one of the hips (Fig. 1) diagnosed by department's orthopaedic surgeon based on interview, clinical examination and imaging examinations (X-ray and CT), full cognition assessed by physiotherapist who conducted functional and balance examinations, presenting complete medical documentation.

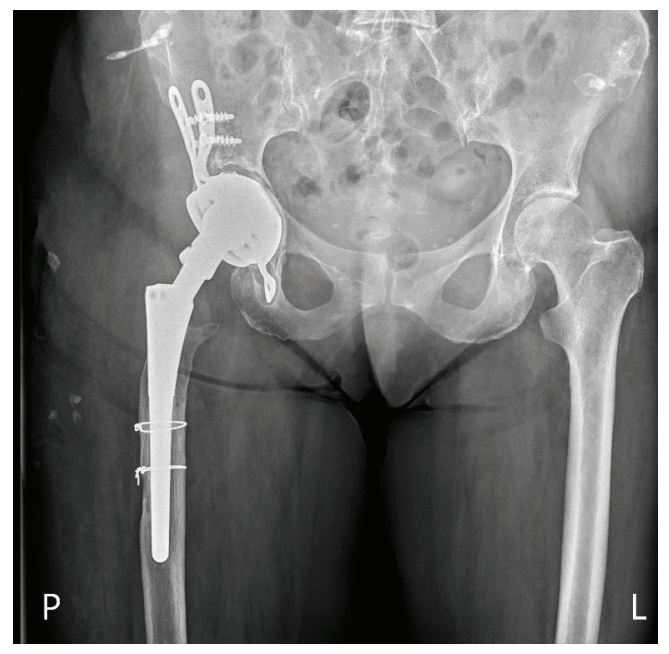

Fig.1. X-ray of a loose total hip replacement prosthesis

Patients with other degenerative disorders or those after surgeries of other joints were excluded from the study. To ensure reliability of the obtained results, patients with neurologic diseases that affect balance, functional states and cognitive processes were excluded. The criteria for subject exclusion were: cranial and cerebral injuries, visual system disorders, neurological disorders, ear and sinus infections, spinal pain, other injuries to the lower extremities, chronic diseases (cancer, Parkinson's disease, epilepsy, diabetes, neuromuscular disorders, unsupervised coronary thrombosis), and taking psychoactive substances.

The static balance test was conducted on bimodular stabilometric platform CQStab2P, registering the movement of centre of foot pressure (COP). It is a reliable measurement tool, and it has received several awards in rehabilitation trade fairs [www.cq.com.pl/n_platforma.htm].

Before joining the study protocol, the patients had been informed on the aim of the conducted measurements, their detailed course, and the possibility to resign at any chosen moment. The data was later verified on the basis of patients' medical documents. 
We analyzed the following parameters (with eyes open and with eyes closed):

SP - the statokinesiogram path (the projection of COP) $[\mathrm{mm}]$,

SPAP - the statokinesiogram path along the $y$-axis [mm],

SPML - the statokinesiogram path along the $x$-axis OX $[\mathrm{mm}]$,

MA - the mean amplitude of COP in two dimensional system of coordinates [mm],

MAAP - the mean amplitude of COP in the anterio-posterior direction $[\mathrm{mm}]$,

MAML - the mean amplitude of COP in the medio-lateral direction $[\mathrm{mm}]$,

MaxAP - the maximum distance between two furthest points in the anterio-posterior direction [mm],

MaxML - the maximum distance between two furthest points in the medio-lateral direction,

MVAP - mean COP velocity on the $y$-axis $[\mathrm{mm} / \mathrm{s}]$,

MVML - mean COP velocity on the $x$-axis $[\mathrm{mm} / \mathrm{s}]$,

SA - the field of COP during the test $\left[\mathrm{mm}^{2}\right]$,

SPSA - the quotient of the statokinesiogram path determined by the COP projection during the test to the field marked by this path $-[1 / \mathrm{dmm}]$.

\section{DB - difference of balance:}

MNDB - mean difference of balance,

MDDB - median of difference of balance,

MinDB - minimum of difference of balance,

MaxDB - maximum of difference of balance

$$
D B(t)=(M L(t)-M P(t)) /(M L(t)+M P(t)) * 100 \%,
$$

$M L(t)$ - mass measured on the left platform at $t$-time,

$M P(t)$ - mass measured on the left platform at $t$-time,

\section{$t$-time,}

RQ - Romberg quotient (the quotient of parameter values with eyes open to parameter values with eyes closed),

RQSP - for the length of path of statokinesiogram,

RQSA - for COP field marked by the movement of COP,

RQMV - for the COP mean velocity in a two-dimensional coordinate system,

RQSPA- for the COP field quotient to the COP path length.

We assessed functional status of the patients on the basis of Harris Hip Score (HHS).

The test was carried out in the morning hours in a specially prepared room. We made sure that the measurements were not disrupted by any noise from the outside.
The subject was asked to rest seated for several seconds. During that time, the equipment was being disinfected and calibrated. Then, the subject was asked to remove footwear and to stand easily on both feet, arms along the body and eyes looking forward. The feet were placed under the hips. There were two $30 \mathrm{sec}-$ ond long trials, the first with eyes open and the second with eyes closed. In the case of the study population, we were not able to use the protocol that provides for three measurements and for calculating the average from all the measurement. We had to use a procedure that based on single measurement, as the patients found it very difficult to maintain balance standing on both feet, and reported uneasiness in the measurement with eyes closed (Fig. 2).

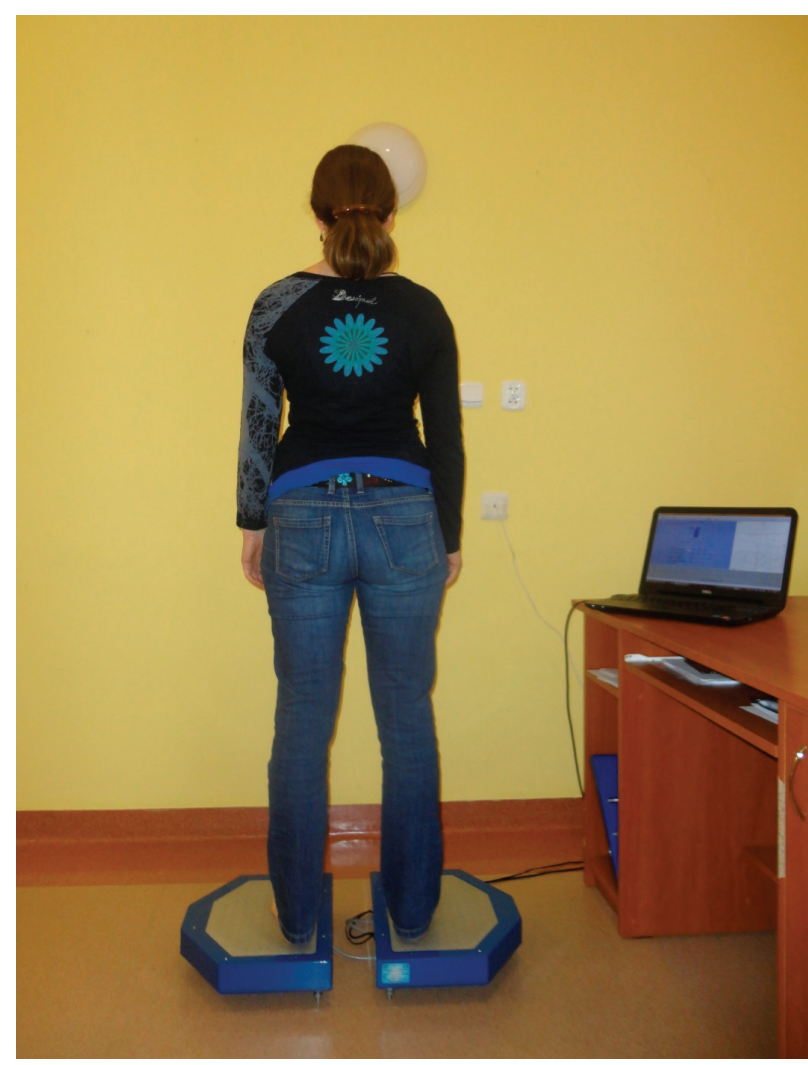

Fig. 2. Model on bi-modular stabilometric platform CQStab2P

\section{Statistical analysis}

A nonparametric Mann-Whitney $U$-test was applied to compare clinical and control groups (as samples taken from independent populations). The Tau-b Kendall rank correlation coefficient has been used to explore correlation between HHS and posturographic characteristics - interval variables whose compliance with the normal distribution has not been confirmed. In all cases, two-sided significance was applied. 


\section{Results}

Our results showed that the mean functional state of the subjects from the study population was 47.23 \pm 16.45 points on the HHS (Harris Hip Score). According to accepted norms, a result lower than 70 points is considered a poor result [6].

Our measurements with eyes open (Table 2) and with eyes closed (Table 3 ) showed significant differences in limb loading. The load to the healthy limb was several times greater.

Table 2. Statistics of posturographic parameters in control and clinical groups with eyes open

\begin{tabular}{|l|c|c|c|c|}
\hline \multirow{2}{*}{ Group } & \multicolumn{2}{|c|}{ Study group } & \multicolumn{2}{c|}{ Control group } \\
\cline { 2 - 5 } & $\bar{X}$ & SD & $\bar{X}$ & SD \\
\hline SP & 248.4 & 125.204 & 224.43 & 112.86 \\
\hline SPAP & 195 & 106.835 & 178.03 & 90.714 \\
\hline SPML & 113.5 & 62.896 & 101.3 & 53.353 \\
\hline MA & 2.9 & 1.53 & 3.27 & 2.06 \\
\hline MAAP & 2.14 & 0.99 & 2.48 & 1.36 \\
\hline MAML & 1.49 & 1.35 & 1.63 & 1.53 \\
\hline MaxAP & 7.92 & 4.33 & 9.73 & 4.74 \\
\hline MaxML & 5.08 & 5.42 & 7.66 & 10.98 \\
\hline MV & 8.28 & 4.17 & 7.48 & 3.77 \\
\hline MVAP & 6.51 & 3.57 & 5.93 & 3.02 \\
\hline MVML & 3.79 & 2.1 & 3.38 & 1.78 \\
\hline SA & 246.47 & 325.29 & 300.33 & 425.35 \\
\hline SPSA & 1.49 & 0.71 & 1.48 & 0.82 \\
\hline MF & 0.49 & 0.23 & 0.41 & 0.14 \\
\hline LWAP & 19.13 & 11.55 & 16.4 & 7.77 \\
\hline LWML & 12.8 & 10.19 & 10.6 & 6.29 \\
\hline MNDB & 22.97 & 19.54 & 12.5 & 10.32 \\
\hline MDDB & 22.77 & 19.75 & 12.67 & 10.51 \\
\hline MinDB & 22.77 & 19.8 & 14.13 & 11.82 \\
\hline MaxDB & 23.83 & 20.93 & 11.67 & 10.75 \\
\hline
\end{tabular}

Table 3. Non-parametric test results for statistically significant differences between control and clinical groups with eyes open (non-significant tests were omitted, all descriptive statistics are presented above)

\begin{tabular}{|c|l|l|c|c|}
\hline & $\begin{array}{c}\text { Mann- } \\
\text { Whitney } \\
U \text {-test }\end{array}$ & $\begin{array}{c}\text { Wilcoxon } \\
W \text {-test }\end{array}$ & $Z$ & $\begin{array}{c}\text { Asymptotic } \\
\text { significance } \\
\text { (bilateral) }\end{array}$ \\
\hline MNDB & 307 & 772 & -2.116 & 0.034 \\
\hline MaxDB & 279.5 & 744.5 & -2.525 & 0.012 \\
\hline
\end{tabular}

Results of tests on the platform with eyes closed showed significantly worse balance in study population patients (Tables 4 and 4a). Their total statokinesiogram path was longer, and their COP sways num- ber was greater. Similarly to the test with eyes open, the load of the healthy limb was much greater.

Table 4. Statistics of posturographic parameters in control and clinical groups with eyes closed

\begin{tabular}{|l|c|c|c|c|}
\hline \multirow{2}{*}{ Group } & \multicolumn{2}{|c|}{ Study population } & \multicolumn{2}{c|}{ Control group } \\
\cline { 2 - 5 } & $\bar{X}$ & SD & $\bar{X}$ & SD \\
\hline SP & 439.57 & 336.98 & 252.92 & 156.79 \\
\hline SPAP & 375.43 & 304.2 & 216.42 & 145.1 \\
\hline SPML & 156.07 & 123.21 & 91.62 & 45.85 \\
\hline MA & 3.8 & 2.32 & 5.06 & 4.29 \\
\hline MAAP & 3.28 & 1.91 & 4.13 & 3.88 \\
\hline MAML & 1.3 & 1.16 & 2.22 & 2.11 \\
\hline MaxAP & 14.15 & 9.27 & 11.92 & 9.05 \\
\hline MaxML & 5.68 & 5.57 & 5.12 & 4.66 \\
\hline MV & 14.66 & 11.23 & 8.43 & 5.23 \\
\hline MVAP & 12.51 & 10.15 & 7.22 & 4.85 \\
\hline MVML & 5.2 & 4.11 & 3.05 & 1.53 \\
\hline SA & 554.5 & 1077.67 & 455.35 & 590.56 \\
\hline SPSA & 1.48 & 0.73 & 1.58 & 1.41 \\
\hline MF & 0.62 & 0.26 & 0.39 & 0.21 \\
\hline LWAP & 25.73 & 13.05 & 13.42 & 9.9 \\
\hline LWML & 22.67 & 11.56 & 7.85 & 8.09 \\
\hline MNDB & 22.87 & 20.67 & 12.62 & 11.81 \\
\hline MDDB & 22.8 & 20.69 & 12.62 & 12.05 \\
\hline MinDB & 22.1 & 18.99 & 14.69 & 12.57 \\
\hline MaxDB & 23.9 & 23.37 & 11.69 & 11.85 \\
\hline
\end{tabular}

Table 4a. Non-parametric test results for statistically significant differences between control and clinical groups with eyes closed (non-significant tests were omitted, all descriptive statistics are presented above)

\begin{tabular}{|l|c|c|c|c|}
\hline Group & $\begin{array}{c}\text { Mann- } \\
\text { Whitney } \\
U \text {-test }\end{array}$ & $\begin{array}{c}\text { Wilcoxon } \\
W \text {-test }\end{array}$ & $Z$ & $p$ \\
\hline SP & 221 & 572 & -2.777 & $\mathbf{0 . 0 0 5}$ \\
\hline SPAP & 225.5 & 576.5 & -2.703 & $\mathbf{0 . 0 0 7}$ \\
\hline SPML & 212 & 563 & -2.925 & $\mathbf{0 . 0 0 3}$ \\
\hline MV & 222 & 573 & -2.761 & 0.006 \\
\hline MVAP & 226.5 & 577.5 & -2.687 & 0.007 \\
\hline MVML & 214 & 565 & -2.895 & $\mathbf{0 . 0 0 4}$ \\
\hline MF & 177 & 528 & -3.5 & $<\mathbf{0 . 0 0 1}$ \\
\hline LWAP & 177 & 528 & -3.502 & $<\mathbf{0 . 0 0 1}$ \\
\hline LWML & 110 & 461 & -4.618 & $<\mathbf{0 . 0 0 1}$ \\
\hline MNDB & 265.5 & 616.5 & -2.048 & $\mathbf{0 . 0 4 1}$ \\
\hline MDDB & 265.5 & 616.5 & -2.047 & $\mathbf{0 . 0 4 1}$ \\
\hline MaxDB & 255.5 & 606.5 & -2.212 & $\mathbf{0 . 0 2 7}$ \\
\hline
\end{tabular}

\section{Correlations with Harris Hip Score (HHS)}

We found a negative correlation between HHS and balance parameters - MaxAP-EC and Max APF (Table 5). Patients with higher HHS presented better 
efficiency in posture control with eyes closed (lower maxiumum AP and APF). It should be remarked, that no analogical dependencies with eyes open reached statistical significance level.

Table 5. Significant Kendall's Tau correlations of balance parameters and HHS

\begin{tabular}{|l|l|c|}
\hline \multirow{2}{*}{ Max AP-EC $[\mathrm{mm}]$} & Correlation coefficient & $-0.338^{* *}$ \\
\cline { 2 - 3 } & Significance (bilateral) & 0.010 \\
\hline \multirow{2}{*}{ MaxAPF-EC } & Correlation coefficient & $-0.387 * *$ \\
\cline { 2 - 3 } & Significance (bilateral) & 0.003 \\
\hline
\end{tabular}

\section{Discussion}

Our results showed differences in balance parameters between the studied groups. This means that the symptom of loosened hip that is revealed in both tests with eyes open and with eyes closed is change in balance. Our results also showed that greater COP sways correlate with worse functional status of patients assessed with HHS.

Without visual control, balance in the clinical control group worsened, which was manifested in longer COP path and greater number of COP sways.

Balance parameters show significant differences in patients with degenerative hip disorders [14]. These parameters improve after surgical treatment [3], [18], allowing for better functional state and return to work [16]. However, there are no studies in the literature on how these parameters change in patients with loosened prosthesis. This is why the aim of our study was to show how the parameters change with loosened hip replacement. The available literature concerns the loosened hip or knee as a serious complications of arthroplasty. Researchers aimed to establish the symptoms and diagnosis, as well as to improve surgical techniques in order to avoid loosening [2]. According to Katz et al. [6], the most common cause for failure of implants was impaired implant fixation (76\%), called aseptic loosening. This complication produces pain and instability, aggravated by activity and weight bearing. The diagnosis of implant loosening is based on clinical symptoms and radiological examinations. In x-rays, a progressive radiolucency line or a width greater than $2 \mathrm{~mm}$ at the bone-implant interface is a sign of aseptic loosening [19]. Another sign of cementless femoral stem loosening is pedestal sign, represented by endosteal bone formation at the distal end of the femoral stem [1]. Aseptic loosening was one of the most common indications for revision, being the cause for revision in $35 \%$ and $23 \%$ of total hip and knee joints surgeries, respectively [8].

Patient clinical status assessed with HHS improves significantly after hip replacement is implanted. This effect continues for several years post-surgery [10]. Our results showed that in patients with loosened hip replacement patient clinical status worsens dramatically.

It has been shown that early decision on exchange of aseptically loosened cementless hip stem prevents an extensive surgery and significantly improves final treatment results [12]. This is why early diagnosis of loosened replacement symptoms is crucial. It allows for early and detailed diagnosis, and for early revision surgery. According to our study, one of the early symptoms might be balance disorders. These disorders may be observed by physiotherapists in noninvasive diagnostic tests prior to physiotherapy. Posturography tests are quick and non-invasive, and our studies show that they allow for early diagnosis of changes to balance parameters.

According to Pop et al. [11], the assessment of balance and postural control should be an integral part of a complex evaluation and monitoring of a patient's functional status at different stages after THR surgery, considering the increased fall risk in this group.

The present study was the first one regarding balance disorders in significant group of patients with serious complication of total hip arthroplasty. The study involved a homogenous group of patients and precisely selected control group. The qualification of patients for the study was conducted by a team of experienced surgeons and physiotherapists, following coherent criteria, which ensured reliability. We found that balance assessment might be an important additional assessment tool.

The balance assessment involved only single measurements with visual control and without visual control, although a larger number of measurements might have given more important information. We had to decide to modify the method because of the severity of condition of our patients.

\section{Conclusions}

1. Hip replacement loosening results in significant worsening of balance parameters.

2. Hip replacement loosening results in significant worsening of patients' clinical status.

3. Postural balance assessment is a useful diagnostic tool in loosened hip replacement. 


\section{Financial support}

The statutory research programme No. DS. 213 Józef Piłsudski University of Physical Education, Warsaw, Poland, funded this study.

\section{Conflict of interests}

The authors declare that they have no conflict of interest.

\section{Data availability statement}

The [exel] data used to support the findings of this study are available from the corresponding author upon request.

\section{References}

[1] Agathangelidis F., Boutsiadis A., Petsatodis G., Pedestal sign in cementless total hip replacement, Hippokratia, 2014, 18 (4), 378.

[2] Apostu D., Lucaciu O., Berce C. et. al., Current methods of preventing aseptic loosening and improving osseointegration of titanium implants in cementless total hip arthroplasty: a review, J. Int. Med. Res., 2018, 46 (6), 2104-2119, DOI: 10.1177/ 0300060517732697. Epub 2017, Nov. 3.

[3] Belaid D., Rougier P., Lamotte D. et al., Clinical and posturographic comparison of patients with recent total hip arthroplasty, Rev. Chir. Orthop. Reparatrice Appar. Mot., 2007, 93 (2), 171-80.

[4] D’Angelo F., Murena L., Zatti G., Cherubino P., The unstable total hip replacement, Indian J. Orthop., 2008, 42 (3), 252-9, DOI: 10.4103/0019-5413.39667.

[5] Gwam C.U., Mistry J.B., Mohamed N.S. et al., Current Epidemiology of Revision Total Hip Arthroplasty in the United States: National Inpatient Sample 2009 to 2013, J. Arthroplasty, 2017, 32 (7), 2088-2092, DOI: 10.1016/j.arth.2017.02.046. E-pub. 2017, Feb. 27.

[6] Kalairajah Y., Azurza K., Hulme C., Molloy S., Drabu K.J., Health outcome measures in the evaluation of total hip arthroplasties - a comparison between the Harris hip score and the Oxford hip score, J. Arthroplasty, 2005, 20(8), 1037-1041.

[7] Katz J.N., Wright J., Wright E.A., Failures of total hip replacement: a population-based perspective, Orthop. J. Harvard Med. Sch., 2007, 9, 101-106

[8] KATZER A., LeEHR J.F., Early loosening of hip replacements: causes, course and diagnosis, J. Orthopaed. Traumatol., 2003, 3, 105-116, DOI: 10.1007/s10195-003-0021-6.
[9] Kempthorne J.T., Ailabouni R., Raniga S. et al., Occult Infection in Aseptic Joint Loosening and the Diagnostic Role of Implant Sonication, Biomed. Res. Int., 2015, 946215, DOI: 10.1155/2015/946215. Epub 2015, Oct. 25.

[10] MJÖBERG B., Does particle disease really exist?, Acta Orthop., 2018, 89 (1), 130-132, DOI: 10.1080/17453674.2017.1373491.

[11] Nolewajka M., GaźDziK T., Jurkiewicz A., The replacement of aseptically loosened cementless acetabula in the hip joint, Ortop. Traumatol. Rehabil., 2003, 30, 5 (2), 238-42.

[12] Pop T., Szymczyk D., MajewsKa J. et al., The Assessment of Static Balance in Patients after Total Hip Replacement in the Period of 2-3 Years after Surgery, Biomed. Res. Int., 2018, 4, 3707254, DOI: 10.1155/2018/3707254, eCollection 2018.

[13] Synder M., KozŁowsKi P., MarciniaK M. et al., Revision hip arthroplasty in aseptic loosening of total hip replacement, Ortop. Traumatol. Rehabil., 2001, 3 (1), 34-37.

[14] TruszczyńsKa A., DobrzyŃSKa M., DrZaŁ-Grabiec J., TRZASKOMA Z., TARNOWSKI A., Assessment of postural stability in patients with lumbar spine chronic disc disease, Acta Bioeng. Biomech., 2016, 4 (18), 71-77.

[15] TRUSZCZyŃSKA A., RĄPAŁA K., GMitrZyKowSKA E., TrZaskoma Z., DrZal-Grabiec J., Postural stability disorders in patients with osteoarthritis of the hip, Acta Bioeng. Biomech. 2014, 1, 45-50.

[16] Truszczyńska A., Trzaskoma Z., Tarnowski A., DrzaŁ-Grabiec J., Dadura E., BiAŁECKI J., The effect of unilateral osteoarthritis of the hip on postural balance disorders, Hip. Int., 2016, 26(6), HIPINT-D-15-00514R2, DOI: 10.5301/hipint.5000395

[17] TRUSZCZyŃSKA A., RĄPAŁA K., KUCHARCZYK W., TARNOWSKi A., TRUSZCZYŃSKI O., Return to work after total hip arthoplasty, Ortop. Traumatol. Rehabil., 2013, 15 (5), 459-467.

[18] TRuszczyŃSKA A., RąPAtA K., TARnOwSKi A., Total hip arthoplasty in degenerative disorders treatment in rural and urban patients. A retrospective randomised controlled study, Ann. Agric. Environ. Med., 2015, 22 (1), 102-105.

[19] TruszczyŃSKA A., DrZAŁ-GrabieC J., RĄaŁA K., GMitrzykowsKa E., Postural Stability in Patients with Osteoarthritis of the Hip. Pilot Study, Ortop. Traumatol. Rehabil., 2013, 15 (6), 567-573

[20] Skyttä E.T., JarkKo L., Antti E., Huhtala H., Ville R., Increasing incidence of hip arthroplasty for primary osteoarthritis in 30- to 59-year-old patients, Acta Orthop., 2011, 82 (1), 1-5, DOI: 10.3109/17453674.2010.548029, E-pub. 2010, Dec. 29.

[21] Vanrusselt J., Vansevenant M., Vanderschueren G., VANHOENACKer F., Postoperative radiograph of the hip arthroplasty: what the radiologist should know, Insights Imaging, 2015, 6 (6), 591-600, DOI: 10.1007/s13244-015-0438-5, Epub 2015, Oct, 20.

[22] WAREŃCZAK A., LisińSKi P., Does total hip replacement impact on postural stability?, BMC Musculoskelet. Disord., 2019, 17, 20 (1), 229, DOI: 10.1186/s12891-019-2598-9. 